\title{
Virtual Mentoring: Practitioner Strategies for Students Underrepresented in Industry
}

\author{
Obed Figueroa ${ }^{1}$ \\ ${ }^{1}$ The American Institute of Graphic Arts, Northeastern University, USA \\ Correspondence: Obed Figueroa, MA, The American Institute of Graphic Arts, Northeastern University, \\ USA. E-mail: figueroa.o@husky.neu.edu
}

\author{
Received: March 17, 2017 Accepted: April 13, 2017 Online Published: May 29, 2017 \\ doi:10.5539/jms.v7n2p144 URL: http://doi.org/10.5539/jms.v7n2p144
}

\begin{abstract}
Technological advancements have continued to develop over the past two decades impacting how we engage with each other. This evolvement has also influenced the way our students and instructors are acquiring and delivering information. In order to sustain the connections with our young people our engagement strategy also needs to evolve. This is especially significant for first generation minority students who are underrepresented in many academic disciplines, industries, particularly in medical education. Research continues to suggest that non-privileged minority groups are less likely to have strong support systems within their social networks and or family. This research paper will provide programmatic frameworks illustrating ways to mentor first generation minority students using virtually tools, learning development models and strategies that help produce positive measureable outcomes.
\end{abstract}

Keywords: mentorship, virtual mentoring, student engagement, minority mentoring

\section{Introduction}

Why is mentorship important? The expression 'pulling yourself up by your boot straps' is misleading and lacks acknowledging the significance of context. It implies, as an analogy, that you have the boots and you know how to tie the shoes. For many first generation college students' persistence within academic programs can be challenging. Research suggests that mentorship can increase college retention and student persistence. Persistence is also mediated by a variety of psychological variables such as motivation and self-awareness (Gregg et al., 2010). In addition environmental factors also influence student success, such as, having systemic supports in place and access to resources. This is where mentorship programs can have a significant impact on a young persons career trajectory. The research article seeks to provide examples of effective mentorship frameworks that are holistic and comprehensive for student engagement.

In considering to participate in a mentoring relationship one should remember the importance of being flexible in order to align with the individualism and the various developmental stages of a mentee. The mentoring dynamic involves two or more and exists as a result of a demonstrated need for guidance. As for the mentor it may involve an individual who is both capable and willing to provide support. Mentorship can be provided in many forms and may be applied informally or formally. The most common approach is the 'one to one' engagement. This traditional approach to mentoring involves an exchange of sharing and listening between two people at a minimum and it may occur over time and evolve. The mentee is often seeking academic advisement, career guidance or life advice from a person who has greater experience. The mentor should be prepared to also provide emotional and cognitive support.

\section{Virtual Mentoring Models}

This research article focuses on virtual mentoring models that have the ability to incorporate various engagement styles. Virtual mentoring involves the use of a computer interface that provides the ability to connect with another party. This engagement could be in the form of text base exchanges, audio, video or any combination. One of the pros of this method is that it provides more flexibility. Opting to use virtual tools to engage with students also elements the challenge of getting to distant locations. Research conducted by Gregg et al., (2010) has identified that virtual engagement often empowers those that tend to be introverts. Furthermore, for those that prefer to use a virtual aviator studies have shown a transfer of positive experiences back to their bodies. This engagement has the ability to transcend across all racial, class and gender lines. This research also aims to 
increase awareness about areas of student development by highlighting where the impact areas are for students of color. Such information will further empower targeted mentoring programs.

Our use of technology in Higher Education has dramatically increased over the past two decades. We have evolved from a Dos and text based computer interface to interactive window based systems with video, audio and live streaming. Educators have the ability to virtually connect with students and have meaningful exchanges beyond the classic 9 to 5 hours. There are multiple virtual tools that can be used such as Google Chat, Skype, Adobe Connect, and Go To Webinar. These tools provide the ability for seamless engagement.

This research also seeks to highlight the importance of providing additional support systems for minority students using virtual tools in a meaningful way to enhance engagement and persistence. Gallien (2005) suggests embedding engagement frameworks that include holistic methods such as the students mind, spirit and emotions. Often times assessments of students' progress is determined by a numerical metric. Viewing grade point averages alone is not comprehensive and does not capture the non-cognitive variables that are equally as important. What are the other dimensions that are critical to student persistence? The Historical Black Colleges and Universities (HBCU's) historically have been successful in retaining, graduating and mentoring students of color at a much higher rate than their counter part institutions. The key to this institutional phenomenon is establishing a context that combines a supportive community culture with high standards (Fleming, 1984). One of the unique qualities of HBCU institutions is that they acknowledge the significance of culture, heritage and support being integrated into the educational experience. In embedding an intentional impact framework into student engagement academic leaders are more likely to see student growth. In addition, educators are more likely to identify key areas for impact and assessment. Student engagement should be flexible to permit the many variables of individual personalities and developmental stages.

\subsection{Model 1}

In a recent research study conducted by Gregg et al., (2016) their team investigated the effectiveness of using virtual mentoring to enhance persistence essential for secondary and post secondary students with disability enrolled in STEM learning (Gregg et al., 2016). Their evidence showed positive results using intentional frameworks and constructs to help enhance persistence and engagement. Their Research uncovered findings from the National Science Foundation that indicated that 1 out of 4 students with a disability enroll in a STEM major (Gregg et al., 2016). In addition, $56 \%$ of students with a disability do not report that they have a learning disability (Newman, et al., 2010). As a result, Gregg et al., (2016) their study reveals that with additional assistance via virtual mentoring, students with a disability can increase their confidence as well as their competencies in areas such as math and science. This virtual program also hoped to reduce some of the barriers often experienced by the students such as traveling, time constraints and costs.

\subsubsection{Program Model}

This virtual mentorship project provided 10 interactive sessions per academic term. The engagement was facilitated online using computer platforms, video, digital voice and text base communications. All participants received a nominal financial award for completing the program. All mentees were provided with the following resources tools: Online resources for learning enhancement in STEM, project-base modules, group activities, networking opportunities and online pre \& post surveys. The study sought to measure the following constructs: aspiration, self-determination, self-advocacy, math and science self-efficacy.

\subsubsection{Research Method}

Using qualitative and quantitative pre \& post surveying the research team administered surveys to secondary and post secondary students. As a requirement participants were selected based on having some form of disability (see appendix A) and were enrolled in a STEM program. The survey sample included secondary education participants $n=98$ and post secondary education participants $n=91$ and asked the participants 67 questions. The survey sample was 188 out of which 151 completed at least one of the surveys. 120 participants were able to complete both. There were 33 mentors participating on this project all of which received online orientation. The majority of the mentors were women and minority educators.

\subsubsection{Findings}

The study identified the influences impacting student persistence. Key areas identified were self-determination, decision-making and the need to control one's life was linked to persistence. In the area of self-determination their research supports that students need a combination of skill, knowledge and beliefs in order to engage in a goal-directed, self-regulated, autonomous behavior (Field, et al., 1998). The driving force behind self-determination is three psychological needs: autonomy, competence and relatedness. Additional research 
studies further supports autonomy and individual choice as having strong correlations to student performance (Deci et al., 2000). These impact areas identified were embedded into the mentoring programs framework. The study showed positive results for the students that were engaged in STEM and the virtual mentoring program. These mentees showed positive academic outcomes (see appendix B) and cognitive growth. The project identified the following; increases in students perception of self-determination, autonomous decision-making and goal setting (Gregg, 2010). Further identified was a positive growth in math and science with the exception of those with learning disabilities

\subsubsection{Discussion}

The virtual mentoring model highlights the benefits of having access to additional supports and resources and how it boosts student's autonomy. Using self-determination theory (SDT) as a guide, it suggests that goals are motivated and shaped by context (Midgley et al., 2000). Researchers also found it critical for mentors to help students identify short-term goals as it contributed to their persistence. The study also showed signs of increased engagement as students began to understand that they had choices and flexibility with their learning experience (Gregg et al., 2010), also observed the strong impact and influence of the mentor engagement.

\subsection{Model 2}

In another study conducted by Kendricks et al., (2013) the team researched the impacts of mentoring from the perspective of minority students. This study reviewed the multiple influencers and impacts in order to examine the effectiveness of mentoring. This study was held at the Central State University (CSU), which is a HBCU with 2400 students out of which $95 \%$ are African American and only 12\% were enrolled in a STEM program. In 2009, the study identified that $59 \%$ of the students at CSU were below the poverty level. As a result, CSU instituted an initiative called the Benjamin Banneker Scholars Program (BBSP). The theory behind the program was 'organizational socialization' which is a process one undergoes to become accustomed to a particular organizational role (Van Maanen et al., 1979). The programs intention was to equip the students with knowledge and skills to be successful in STEM programs.

\subsubsection{Program Model}

Established in 2009, the mission of the Benjamin Banneker Scholars Program (BBSP) was to increase enrollment, retention and performance for students underrepresented in STEM programs by providing mentoring supports. The student to faculty ratio was 4 to 1 . Program participants received a stipend of $\$ 7,500$ per year, which was to be applied to tuition, room and board. The faculty also received a stipend for participating in the program. As a requirement of the program students engaged in the following experiences:

1) Academic Learning via enrollment in two STEM courses per term maintaining a GPA of 3.0

2) Participants must reside in the 'Honors Dorm.'

3) Attend mandatory monthly and individual meetings $w /$ mentor

4) Attend professional development workshops

5) Visit graduate STEM programs two are required per year

6) Participate in internships and undergraduate research

7) Complete a pre \& post surveys evaluating all the above (Kendricks, 2013)

\subsubsection{Research Method}

The studies length was one full year and the program study participants were 20 freshmen to seniors. The research study used both qualitative and quantitative pre \& post surveys to acquire the impact from the mentee's perspective. The survey type used a Likert 5 point scale, which evaluated key impact areas for 20 post secondary students. The areas of review were; academic performance, program participation \& satisfaction, frequency of research engagement and career exploration. The program also hired an external evaluator to review student coursework three different periods throughout the semester in order to determine program impact.

\subsubsection{Findings}

The BBSP program and the study provided insightful results that included reactions from the mentee's perspective. The best improvements were shown by the $5^{\text {th }}$ week of the program. Most of the cohort of students had a hard time abandoning their old practices and belief. The majority of the mentee's felt that they gain valuable academic support from the program. The average grade point average ranged from 3.0 for term one and 3.2 for term two. The study found the biggest academic gains achieved were in biology and math. In the area of computer science there were modest gains shown but in chemistry and physics there was a noticeable drop (see 
appendix C).

\subsubsection{Discussion}

The BBSP virtual mentorship program was very intentional. The study highlights the positive influences and impacts of the mentorship connection. All of the mentor's entering the program understood that there maybe times where they need to serve as an extended family member to the mentee. This was found to be one of the most endearing qualities of the program. The mentor's were often engaging beyond academic supports. The program also identified that the mentee's success was better assured if there were multiple support systems in place. As a result, the program created a network of mentors that included interested industry leaders and members of the student's family. In addition, the mentor's also provided career advice and often leveraged their own social capital to further assist their mentee's. The program also demonstrated high engagement from the mentors, which included attending conferences and special events with their mentee.

Guiffrida (2005) provides additional insight in understanding of the unique relationship between African American mentee's and a mentor. Guiffrida coined the term 'Othermothering' that helps explains a condition that dates back to slavery from the displacement experienced by young people of African decent. As a result, it was common for young people of color back then to find support from others that were not their family. This condition also gave rise to the expression, 'It takes a village to raise a child.' This expression continues to give support to the notion that collaborative supports can empower young people.

\subsection{Model 3}

Diverse Medicine, established in 2012, is a web-based mentoring program for pre-medical and medical students studying the health sciences. The program mission is to increase ethnic and socioeconomic diversity within the field of medicine. Dr. Dale Okorodudu, founder, is a practicing Pulmonary and Critical Care physician at the Dallas VA Medical Center. The program provides mentors that are credentialed healthcare providers that fundamentally believe that individuals from underrepresented or disadvantage ethnic groups are capable of becoming highly effective clinicians and scientists if provided with community of support systems and mentorship. The following engagement tracks are available: High School, Early Premed, Applying Premed, Post-Bac Student, $1^{\text {st }} \& 2^{\text {nd }}$ year med students, $3^{\text {rd }} \& 4^{\text {th }}$ year med students and medical graduates in residency. Each of these levels represents an academic stage which becomes the bases for targeted discussions.

The program provides accessibility to industry leaders by means of a web-based platform. The mentors are all credentialed healthcare providers all having excelled in there own academic experience. In addition, their pursuit of study in medicine has varied. This provides the teams of mentors with the ability to match with a wide spectrum of mentee's from different backgrounds. Selectively chosen, Dr. Okorodudu states, "our mentors have a long history of demonstrating a dedication to industry and they continue to show a strong commitment to the next generation of healthcare professionals" (D. Okorodudu, personal communication, April 9, 2017). All of the mentors undergo an orientation process to assure their readiness for program engagement.

\subsubsection{Program Model}

The program is annual and provides access to mentee's at no cost from September to June. The curriculum is designed to match the academic level of the mentee. Each track provides targeted monthly discussions that are aligned with the student's current career level. The program also acknowledges the importance of integrating relatability, academic support and career advice. The program format also provides the flexibility for the mentee to choose the resources that best match their needs. However, the mentor may make recommendations based on the exchanges with the mentee. This web-based program provides the following resources and engagement opportunities:

- Access to industry leaders

- One to One mentoring

- Virtual lecture series

- Educational videos

- Clinical case reviews

- Mock interviews

- $\quad$ Essay and resume/CV reviews (Diverse Medicine, 2017) 


\subsubsection{Findings}

In an interview conducted with Dr. Okorodudu he stated, "our program started in 2012 with 20 students and now we have grown to 75" (D. Okorodudu, personal communication, April 9, 2017). This represents a growth rate of nearly $300 \%$ and the founder wishes to keep the enrollment small to better assure the quality of the program. In an analysis conducted by his team the mentor's expressed challenges in consistency with student engagement due to a lack of commitment from a small percentage of the mentees. Dr. Okorodudu stated, "It is unfortunate that some do not realize the opportunity and positive influence this engagement has on a career" (D. Okorodudu, personal communication, April 9, 2017). The majority of the mentee's make their monthly sessions with their mentors without a problem largely due to the flexibility of the web-based program. The program has thus far has influenced over 1,000 students of color studying the health sciences. This platform continues to provide the opportunity to influence young adults by having health professionals engage with pre-medical and medical students as they actively experience the journey to practitioner.

\subsubsection{Discussions}

Why is this significant? In the field of medicine minority recruitment and retention continues to be a challenge for the medical industry. Frequently identified as a contributor to this challenge, in part, is the lack of exposure to industry and or mentorship to guide young people to study medicine. In the 2016-17 annual report from the Association of American Medical Colleges (AAMC) the data shows 53,042 applicants applying to medical school, out of which 21,030 matriculated into medical schools (AAMC, 2016). The report identifies that for men and women there is almost equal representation in the areas of enrollment where men represent $50.2 \%$ and women $49.8 \%$. This is a good sign for gender equity however the same cannot be said for ethnic groups underrepresented in medicine (URM's). The annual AAMC report shows low medical school enrollments for African American's at $7.1 \%$ and Hispanic's at $6.3 \%$ as compared to Caucasians enrollment rates that are at $51.48 \%$ (AAMC, 2016).

There are some universities where they are the exception to this low enrollment challenge. For example, Historical Black Colleges and Universities (HBCU'S) like Howard University College of Medicine and Meharry Medical College or Ponce Health Sciences and the University of Puerto Rico School of Medicine where these schools have minority enrollments averaging over $60 \%$. These institutions offer by example valuable lessons on why and how they are able to recruit, retain students of color.

The Diverse Mentoring program provides the opportunity for young people to gain access and awareness to the study of medicine. This approach reduces any financial barriers and allows the mentee to connect directly industry leaders. This is critical for students that may come from economically disadvantaged communities as more often then they will not have access to the social capital to connect with professionals in industry. The program also provides a resource listing for summer programs that are science based. This provides the opportunity for exposure to industry and to a community with a common interest.

\section{Conclusion}

This research has the intention of informing industry leaders about additional, low cost, web-based strategies that offer intentional impact frameworks to engage students of color. In addition, industry leaders seeking to mentor should become familiar with a few developmental theories and student engagement models to best assure that their strategy is informed. It is always beneficial for leaders to gain additional insights on best practices. In a research study from the Black Caucus of the Society for Research in Child Development they found that there were important framework leaders should keep in mind when they are seeking to engage and retain African American students. First, culturally appropriate and diverse instruction that provides some forms of relatedness. Secondly, provide role models from similar cultural backgrounds that are competent in academic content. Lastly, to remember the importance of context by assuring that there are institutional supports in place, which may include financial and infrastructure supports. Students in this engagement will also seek to have visibility and active participation (Slaughter et al., 2006).

Our society and the diverse populations that coexist with each other are very complex. To avoid stereotyping, it is important to remember that not all minorities groups are economically challenged and or educationally disadvantaged. As educators engage with new groups and or an individual mentees it is important to be open minded and listen to the unique needs that are being presented.

The commonalities between the programs presented in this paper are multiple as each offer frameworks that embed strategies to increase autonomy, self-efficacy, self-determination and academic persistence. Also embedded are examples of intentional frameworks that acknowledge the importance of relatability, support, academic supports and career advice. Finally, It goes without saying without knowledgeable, empathic, industry 
leaders none of these programs would be sustainable and for that we all have much admiration and gratitude.

\section{References}

American Psychological Association. (2017). Introduction to Mentoring: A Guide for Mentors and Mentees. (2017). Retrieved from http://www.apa.org/education/grad/mentoring.aspx

Deci, E. L., \& Ryan, R. M. (2000). The "what" and "why" of goal pursuits: Human needs and the self-determination of behavior. Psychological Inquiry, 11, 227-268. https://doi.org/10.1207/S15327965PLI1104_01

Diverse Medicine. (2017). Diverse Medicine. Retrieved from http://www.diversemedicine.org/\#sthash.PirEVaQG.dpbs http://www.diversemedicine.org/mentoring-curriculum\#sthash.NSEgk4F5.0rVxlnQP.dpbs

FACTS: Applicants, Matriculants, Enrollment, Graduates, MD/PhD, and Residency Applicants Data—Data and Analysis-AAMC. (2017). Retrieved from https://www.aamc.org/data/facts/

Field, S., Martin, J. E., Miller, R., Ward, M. J., \& Wehmeyer, M. L. (1998). Self-determination for persons with disabilities: A position statement of the Division on Career Development and Transition. Career Development for Exceptional Individuals, 21, 113-128. https://doi.org/10.1177/088572889802100202

Fleming, J. (1984). Blacks in college: A comparative study of students success in black and in white institutions. San Francisco: Jossey-Bass Publications.

Gallien, Jr., \& Peterson, M. (2005). Instructing and mentoring the African American College Student. New York: Pearsons Education Inc.

Gregg, N., Galyardt, A., Wolfe, G., Moon, N., \& Todd, R. (2016). Virtual Mentoring and Persistence in STEM for Students with Disabilities. Career Development and Transition for Exceptional Individuals, 2016. https://doi.org/10.1177/2165143416651717

Guiffrida, D. (2005). "Othermothering” as a framework for understanding African American students' definitions of student-centered faculty. The Journal of Higher Education, 76, 701-723. https://doi.org/10.1353/jhe.2005.0041

Kendricks, K. D., Nedunuri, K. V., \& Arment, A. R. (2013). Minority Student Perceptions of the Impact of Mentoring to Enhance Academic Performance in STEM Disciplines. Journal of STEM Education: Innovations \& Research, 14(2), 38-46. Education Research Complete, EBSCO host.

Midgley, C., Maehr, M. L., Hruda, L. Z., Anderman, E., Anderman, L., Freeman, K. E., \& Urdan, T. (2000). Manual for the Patterns of Adaptive Learning Scales. Ann Arbor: University of Michigan.

Newman, L. A., \& Madaus, J. W. (2015). An Analysis of Factors Related to Receipt of Accommodations and Services by Postsecondary Students With Disabilities. Remedial and Special Education, 36(4), 208-219. https://doi.org/10.1177/0741932515572912

Van Maanen, J., \& Schein, E. (1979). Toward a theory of organizational socialization. Research in Organizational Behavior, 1, 209-264.

\section{Appendix A}

The Types of Disabilities Disclosed Within the Survey Sample

\begin{tabular}{lccccc}
\hline Institution & LD (n) & ADD/ADHD (n) & ASD (n) & Psych (n) & Other (n) \\
\hline Secondary & $59 \%(54)$ & $16 \%(15)$ & $13 \%(12)$ & $0 \%(0)$ & $11 \%(10)$ \\
Postsecondary & $24 \%(24)$ & $29 \%(28)$ & $4 \%(4)$ & $22 \%(22)$ & $20 \%(20)$ \\
\hline
\end{tabular}

Note $L D=$ learning disablilites; $A D D=$ attention-defict disorder, $A D H D=$ attention-deficithyperactlvity disorder, $A S D=$ autlsm spectrum disorder, Psych = psychological disorders (USG-identffled category); other = motor, perceptual, and health disorders; USG = University System of Georgla 


\section{Appendix B}

\section{Survey Results Illustrating Impact Factors}

\begin{tabular}{|c|c|c|}
\hline Factor & Loading & Survey question \\
\hline \multirow[t]{5}{*}{ Self-determination } & 0.90 & I begin working on my plans to meet my goals as soon as possible. \\
\hline & 0.83 & I set goals to get what I want or need. I think about what I am good at when I do this. \\
\hline & 0.78 & If my plan doesn't work, I try another one to meet my goals. \\
\hline & 0.78 & I know what I need, what I like, and what I'm good at. \\
\hline & 0.76 & I figure out how to meet my goals. I make plans and decide what I should do. \\
\hline \multirow[t]{5}{*}{ Self-advocacy } & 0.91 & $\begin{array}{l}\text { I can effectively use academic accommodations (like extra time, screen readers, etc.) in } \\
\text { all my classes. }\end{array}$ \\
\hline & 0.90 & $\begin{array}{l}\text { I can list and discuss the academic accommodations (Iike extra time, screen readers, } \\
\text { etc.) I need to be successful in school. }\end{array}$ \\
\hline & 0.88 & $\begin{array}{l}\text { I can independently request academic accommodation (like extra time, screen readers, } \\
\text { etc.) in all my classes. }\end{array}$ \\
\hline & 0.83 & $\begin{array}{l}\text { I can list and discuss the accommodations (like extra time, screen readers, etc.) I will } \\
\text { use to be successful in my job. }\end{array}$ \\
\hline & 0.81 & I can list and discuss the support services I will need in college in order to be successful. \\
\hline \multirow[t]{5}{*}{ Aspirations } & 0.94 & Someday, I would like to have a career in math or science. \\
\hline & 0.92 & I intend to get a degree in either math or science. \\
\hline & 0.92 & I intend to devote my career to math or science. \\
\hline & 0.86 & I would take an internship position in math or science if it were available. \\
\hline & 0.74 & I can see myself working as a scientist or mathematician. \\
\hline \multirow[t]{5}{*}{ Math self-efficacy } & 0.88 & I worry about my ability to solve math problems. \\
\hline & 0.85 & Doing math makes me feel nervous. \\
\hline & 0.82 & I get a sinking feeling when I try to do math problems. \\
\hline & 0.79 & My mind goes blank and I am unable to think clearly when doing a math test. \\
\hline & 0.76 & Math makes me feel uneasy. \\
\hline \multirow[t]{5}{*}{ Math interest } & 0.86 & I find math interesting \\
\hline & 0.80 & Math is one of my favorite subjects. \\
\hline & 0.69 & I enjoy learning math. \\
\hline & 0.65 & I would like to take more math classes. \\
\hline & 0.62 & I think that I will use math in the future. \\
\hline \multirow[t]{5}{*}{ Science self-efficacy } & 0.76 & I am nervous about how I will do on science tests. \\
\hline & 0.68 & I worry about failing science tests. \\
\hline & 0.64 & I become anxious when it is time to take a science test. \\
\hline & 0.57 & I hate taking science tests. \\
\hline & 0.46 & It makes me nervous to even think about doing a science experiment. \\
\hline \multirow[t]{5}{*}{ Science interest } & 0.48 & Understanding science gives me a sense of accomplishment. \\
\hline & -0.41 & I do things the same way even if there might be a better way. \\
\hline & 0.39 & I find learning science interesting. \\
\hline & 0.38 & Earning a good science grade is important to me. \\
\hline & -0.36 & I can only think of one way to get something I want. \\
\hline
\end{tabular}

Note. Includes the five items with the highest loadings in each factor.

Note. This data is adapted from (Gregg et al., 2016). 


\section{Appendix C}

\section{BBSP Mentoring Programs Impact on Academic Performance}

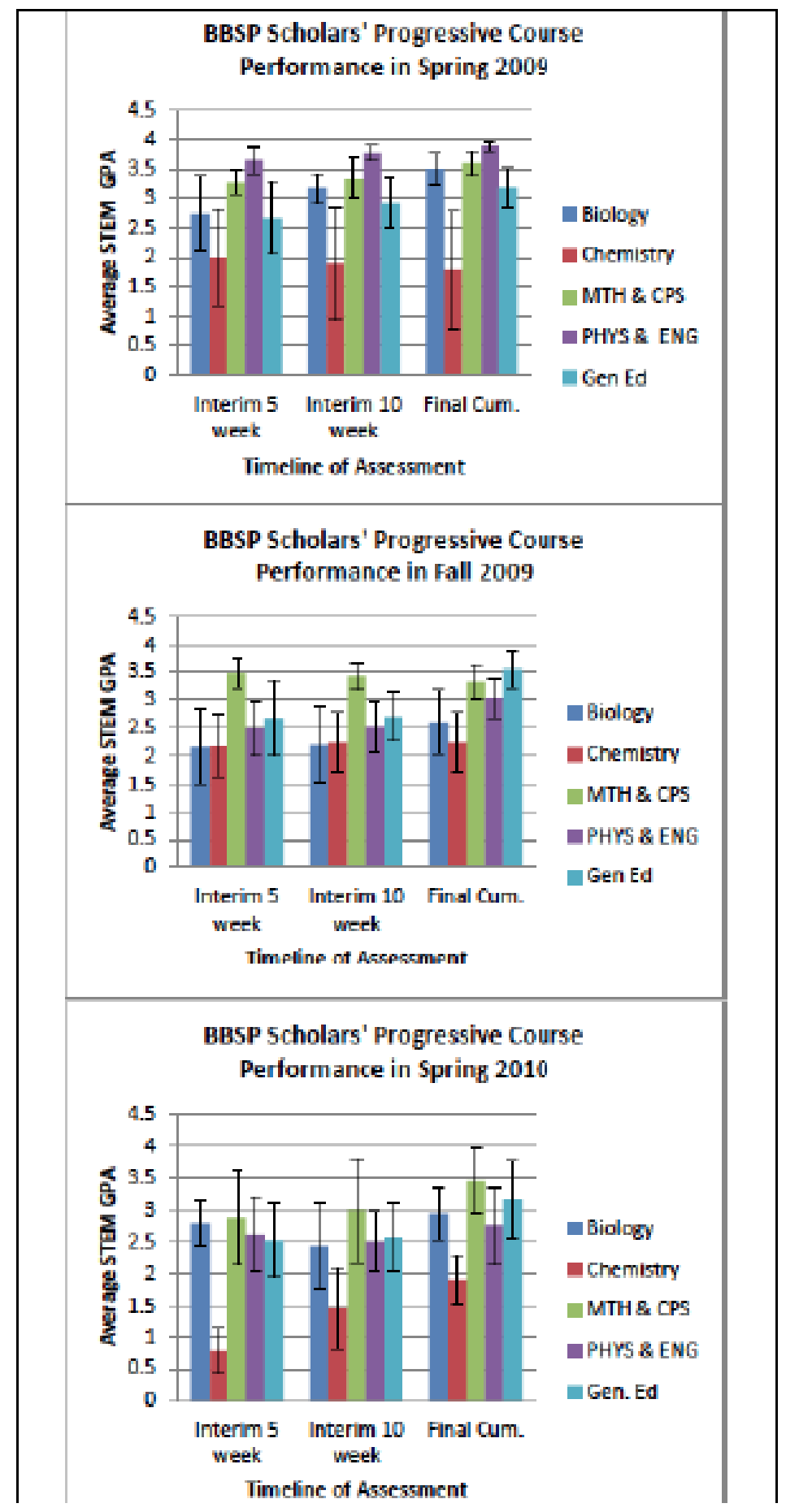

Note. The data was adapted from (Kendricks et al., 2013).

\section{Copyrights}

Copyright for this article is retained by the author(s), with first publication rights granted to the journal.

This is an open-access article distributed under the terms and conditions of the Creative Commons Attribution license (http://creativecommons.org/licenses/by/4.0/). 